\title{
ECONOMIA DO GRUPO KAINGANG DO OESTE PAULISTA NA TERRA INDÍGENA VANUÍRE
}

\author{
ECONOMY OF THE KAINGANG GROUP OF WEST PAULISTA ON TERRA INDÍGENA VANUINE \\ ECONOMÍA DEL GRUPO KAINGANG DE PAULISTA OCCIDENTAL EN TIERRAS INDÍGENAS DE VANUINA
}

\begin{abstract}
Francisco Gilson Rebouças Porto Júnior
Doutor em Comunicação e Cultura Contemporâneas pela Faculdade de Comunicação da Universidade Federal da Bahia. Professor da Fundação Universidade Federal do Tocantins (UFT) e do Programa de PósGraduação em Propriedade Intelectual e Transferência de Tecnologia para a Inovação (PROFNIT-UFT). gilsonportouft@gmail.com.
\end{abstract}

\section{0-0002-5335-6428}

\section{Valquiria Cristina Martins}

Mestranda em Agronegócio e Desenvolvimento pela UNESP/ Campus de Tupã. Membro do grupo PGEA. Educadora de Museus. valcrismar@gmail.com.

0000-0002-8445-4207

\section{Nelson Russo de Moraes}

Livre Docente do Programa de Pós Graduação em Agronegócio e Desenvolvimento na UNESP/Campus Tupã. Doutor em Comunicação e Cultura Contemporânea, pela Universidade Federal da Bahia. Líder do Grupo de Estudos em Democracia e Gestão Social. nelsonrusso.unesp@gmail.com.

0000-0003-0159-9433

\section{Cristiane T. B. Marchetti}

Mestranda em Agronegócio e Desenvolvimento pela Faculdade de Ciências e Engenharia/FCE/Tupã UNESP. cris.bazilio@hotmail.com.

0000-0002-7833-2975

\section{Anderson da C. Lacerda}

Programa de Pós-Graduação em Ciência, Tecnologias e Inclusão, Instituto de Biologia, Universidade Federal

\author{
Fluminense, Niterói \\ costadelacerda@gmail.com. \\ RJ, Brasil \\ 0000-0002-1862-2743
}

Correspondência: Universidade Federal do Tocantins (UFT), Avenida NS-15, Quadra 109, Norte, s/n - Plano Diretor Norte, 77001-090 - Palmas, TO - Brasil.

Recebido em: 12.10.2020.

Aceito em: 20.11.2020.

Publicado em: 01.01.2021.

\begin{abstract}
RESUMO:
$O$ presente artigo tem como objetivo descrever o conteúdo histórico e etnográfico do grupo Kaingang do Oeste Paulista, na Terra Indígena Vanuíre, e como promovem sua economia. Os Kaingang são povos pertencentes ao tronco linguístico Macro-Jê, e família Jê, é considerado um dos maiores grupos indígenas do ponto de vista populacional. A metodologia adotada para o desenvolvimento deste artigo parte da tipologia bibliográfica e descritiva, tendo como técnica a pesquisa documental. Espera-se obter, com deste artigo, um conjunto sistematizado de informações, que ao alcançar o objetivo do trabalho, possa contribuir para o melhor entendimento sobre a economia do grupo Kaingang do Oeste Paulista, na Terra Indígena Vanuíre.
\end{abstract}

PALAVRAS-CHAVE: Etnodesenvolvimento; Kaingang; Terra Indígena Vanuíre.

\section{Introdução}

Um dos grupos indígenas com maior população no território brasileiro encontramse os Kaingang, são aproximadamente 34 mil indígenas, o que corresponde a quase $50 \%$ de toda população de língua Jê. Estão entre os cinco povos indígenas mais populosos no Brasil (ANDRIOLLI; CANDIDO, 2020).

O percurso histórico cultural deste grupo passou por diversas modificações, incitada, principalmente pelo avanço e pressões de nossa sociedade capitalista, estes, muito pouco tentaram compreender a cultura indígena, em seu objetivo não consta o fortalecimento cultural e permanência milenar dos costumes locais, o respeito aos hábitos alimentares e deixar uma contribuição, com uma melhor qualidade de vida, 
daqueles que se encontravam nestas terras, antes da chegada dos bandeirantes. Não era o foco destes, que os povos indígenas pudessem desenvolver as mais variadas atividades para o fortalecimento de sua economia.

Os Kaingang, em sua economia tradicional tem o cultivo da agricultura dentre as quais podemos citar algumas: a mandioca, o milho bugre/roxo, algumas ervas medicinais, árvores frutíferas. Também a pesca, a confecção de diferentes adornos (D'ANGELIS; VEIGA, 2009).

Percebe-se que somente algumas terras Indígenas a solo fértil para o plantio, outras regiões quando semeadas, pode ocorrer: secas, enchentes, geadas, situações as quais podem comprometer a economia indígena segundo Baptista (2008). Acrescenta se que poucas vezes há algum rio que passe por suas terras onde poderão realizar a pesca tradicional com covo, ou pesca de loca.

O presente artigo tem como objetivo geral compreender, uma pesquisa bibliográfica histórica e etnográfica, em como o grupo Kaingang do Oeste Paulista na Terra Indígena Vanuíre promove sua economia.

Enquanto objetivo especifico pretende-se caracterizar a cultura do grupo Kaingang do Oeste Paulista, na Terra Indígena Vanuíre, frente sua economia; Compreender o teor histórico e etnográfico do grupo Kaingang do Oeste Paulista, na Terra Indígena Vanuíre, e como promovem sua economia; Identificar a economia do grupo Kaingang do Oeste Paulista na Terra Indígena Vanuíre.

Para tanto enquanto metodologia, como forma de se atingir o objetivo proposto o presente artigo será desenvolvido por uma estrutura analítica descritiva de ações conforme descrito abaixo.

Levantamento bibliográfico aprofundado nas bases de dados online, pesquisando por artigos acadêmicos científicos e livros clássicos bem como sites ligados a questões indígenas como Fundação Nacional do Índio (FUNAI), Museu Histórico e Pedagógico Índia Vanuíre (MHPIV), Instituto Socioambiental (ISA), Museu do Índio, buscas documentais em outros Órgãos Governamentais e Não Governamentais, sendo que para a pesquisa deste artigo serão utilizadas como principais descritores as palavras: Kaingang, etnodesenvolvimento, agricultura, economia indígena, etnconhecimento, dentre outras que se fizerem necessárias.

\section{Os Kaingang do oeste paulista na terra indígena Vanuíre}

Um país continental, o Brasil, com uma biodiversidade ambiental, cultural e social, se estabelece como a regra e não a exceção na socialização e na convivência entre os indivíduos de suas diversas regiões. Com extensões territoriais longínquas riquíssimos 
em sua fauna e flora, e em seus aspectos culturais, fundamentando o tradicionalismo de boa parte de sua população, especialmente no interior (MORAES et al., 2016).

O Grupo Kaingang, segundo ISA (2020), foi inserido no final do século XIX por Telêmaco Borba, inicialmente, os Kaingang e os Xokleng foram classificados como uma só comunidade indígena, mesmo com dialetos diferentes. Porém, com a separação histórica, cada etnia desenvolveu seu método sociocultural, tornando-os distintos.

Historicamente os Kaingang não se diferem dentre outros povos indígenas, com atos de violência praticados pela sociedade a estes, são diversos registros contabilizados por anos de massacre e etnocídio devido ao capitalismo. Pinheiro (1999) explica que no século XX:

A primeira metade deste século, principalmente os anos 30 e 40, conforme analisados na fala dos constituintes de 1933 e 1934, por Zélia Lopes da Silva e pelos historiadores Silvia H. Z. Martins e Janete Leiko Tanno4 apresentam várias estratégias utilizadas pela classe dominante para controlar a população pobre e reordená-la sob-regras e planos racionalizantes. (PINHEIRO, 1999, p. 15).

As mais variadas tentativas de controlar a população indígena inclui a territorialidade da comunidade Kaingang, deixando grandes sequelas.

De acordo com Silva e Laroque (2012):

Tradicionalmente, os indígenas Kaingang ocupavam uma imensa área do Brasil Meridional, esta compreendia desde a região Sudeste até o extremo sul do Brasil, formando assim "O Grande Território Kaingang". Os limites dessa ocupação abrangiam desde o rio Tietê, no sudeste, passando pelos Estados de Paraná, Santa Catarina e Rio Grande do Sul, o território se estendia até os rios Jacuí e Ibicuí. Para o oeste, a ocupação Kaingang avançava para a província argentina de Misiones. (SILVA; LAROQUE, 2012, p. 436).

Logo Bussoli (2018) conclui que:

Expulsos de seus territórios tradicionais a partir de meados do século XVIII e durante o século XIX, os Kaingang jamais deixaram de circular por seus territórios tradicionais e, sobretudo a partir da segunda metade do século XX no Rio Grande do Sul, passaram a empreender um processo de retomada das suas terras. (BUSSOLI, 2018, p. 12-13).

Segundo ISA (2020), os Kaingang são do tronco linguístico Marco-Jê, pertencente à família Jê e "[...] chegaram ao sul e sudeste do Brasil há 3.000 anos [...]". Assim, na história deste grupo podemos destacar, como um dos pontos de partida, este momento, tendo um dos seus registros histórico, no oeste paulista. (MHPIV, 2020, p. 01).

No século XVII foi registrada a presença do Kaingang: 
[...] no curso superior do rio Uruguai e no século XVIII ocupavam as extensas florestas do alto Uruguai, numa área que vai do rio Piratini (extremo Oeste) até a bacia do rio Caí, a leste. Constituíam territórios kaingang o Oeste de São Paulo, terras do segundo e terceiro planaltos do Paraná e Santa Catarina e toda a faixa acima das bacias dos rios Piratini, Jacuí e Caí no Rio Grande do Sul (ISA, 2020, p. 01).

Gonçalves (2007) acrescenta que:

Os Kaingang hoje são considerados um dos cinco povos indígenas mais populosos da Brasil, com aproximadamente 30 mil pessoas distribuídas em cerca de 30 áreas indígenas diferentes entre os Estados de São Paulo, Paraná, Santa Catarina e Rio Grande do Sul. (Gonçalves, 2007, p. 02).

Os Kaingang, na Alta Paulista, ocuparam as terras mais elevadas de cerrado conhecida como espigões, margeando os rios Tietê, do Peixe, Aguapeí conhecido Feio e Paranapanema onde se localiza o município de Tupã (MELATTI, 1976; PINHEIRO, 1992; MHPIV, 2020).

Pinheiro (1999) fornece maiores detalhes sobre o grupo Kaingang do oeste paulista:

A Aldeia Vanuíre distante da cidade de Tupã $23 \mathrm{~km}$, sentido aeroporto. Abrange uma área de 604 hectares (ha). Banhada pelos córregos Pirã, Koiós e lakri. A área indígena é cortada três vezes pela estrada municipal, em sentidos diferentes. (PINHEIRO, 1999, p. 11).

A colonização da região do oeste do estado de São Paulo concretizou-se a partir do início do século $\mathrm{XX}$, anteriormente, toda a área cortada pelos Rios São José dos dourados, Tietê, Rio Aguapeí/Feio, Rio do Peixe e Santo Anastácio era considerados o sertão desconhecido habitado por indígenas (MONTEIRO, et al., 1984).

Em meados do século XIX e início do século XX processos de reconhecimento, de colonização e de ocupação deste território, estavam em andamento, por meio das expedições exploratórias, organizados por comissões e instituições científicas, algumas de cunho religioso, com o objetivo de catequizar os indígenas encontrados, entre suas metas estava a expansão da economia cafeeira e a construção de novas vias de comunicação, dentre elas as ferrovias (MONTEIRO, et al., 1984).

Segundo Ribeiro (1988, p. 93):

a expansão da floresta Atlântica avançava pelas vertentes orientais da serra do mar, acompanhando o curso dos rios que corre para o oeste, como o rio Grande, o Tietê, o Paranapanema, o Ivaí e o Iguaçu, eram as 
grandes matas e norte do Paraná que cobriam grande parte do Estado de São Paulo, sul de Minas Gerais.

A cultura do café tem por ímpeto a lavoura de exportação, como uma importante atividade econômica do país, para a época. (RIBEIRO, 1988). Com tal avanço, no ano de 1905 deu-se início a construção da Estrada de Ferro Noroeste do Brasil. Neste momento iniciou-se também o conflito, que se intensificou entre os Kaingang e não indígenas (VEIGA, 2006; MONTEIRO et al., 1984).

A estrada de ferro naquele período tinha como objetivo estreitar a distância entre as cidades e impulsionar o desenvolvimento da economia cafeeira no Estado de São Paulo, algo que não teria sido possível sem a expansão da linha férrea (MONTEIRO, et al., 1984).

Com a criação da estrada de ferro que ligaria Santos a Corumbá, afetando as Terras Indígenas Kaingang, surgem nesse contexto os grileiros que adquiriam terras férteis a baixo custo (RIBEIRO, 2009).

Neste período, "[...] para a sociedade expansionista a terra paulista nesse momento era mais um importante elemento da produção econômica de mercadorias para a exportação [...]" (PINHEIRO, 1992, p. 39).

Pelo fato do município de Bauru fazer uma ligação com outras ferrovias Sorocabana e companhia Paulista, foi escolhido como ponto inicial para a construção da linha férrea (MELATTI, 1976; RODRIGUES, 2016).

Portanto, com a expansão do café e da linha férrea na Alta Paulista, os Kaingang além de começaram a sofrer com várias intervenções em sua dinâmica social e no modo de ocupação do seu espaço territorial, eram considerados como um impedimento ao modelo do crescimento econômico da região, pelo fato de defenderem o território em que habitavam. Os fazendeiros, políticos, e bugreiros estes contratados por fazendeiros motivados pela expansão dadas cafeicultura lutavam pela posse privada das terras (RODRIGUES, 2007; RIBEIRO, 2009).

Os Kaingang "[...] passaram a ter seus territórios invadidos pelo governo do Estado e pelos colonizadores que, de forma articulada, iam construindo a estrada de ferro rumo ao sertão que era na verdade território Kaingang [...]" (ISA, 2020, p. 01).

É nesse momento que começa o impasse entre os Kaingang, que por sua vez para defenderem seu território que estava sendo invadido pelos fazendeiros, grileiros, destruíam a estrada de ferro em construção para amedrontar os funcionários de empresas, esses funcionários diante o impasse, contratavam bugreiros para perseguir assassinar, os Kaingang, por meio do uso de armas e/ou contaminação por doenças ocasionando a morte em massa (RIBEIRO, 2009; CURY, FABRRI, 2019). 
Os bugreiros invadiam as Terras Kaingang, "[...] devastando roças, queimando casebres e matando homens, mulheres e crianças. Os trabalhadores da estrada, também fortemente armados, compraziam-se em atirar a esmo, mata adentro, e a espingardear qualquer índio que divisassem [...]" (RIBEIRO, 1988, p. 142).

Eram entregues roupas contaminadas de Varíola, mulheres e crianças indígenas também eram aprisionadas para chamar atenção dos homens, dentre outras formas sutis e desbravadoras, como ofertas de bebidas alcoólicas, os maiores massacres ocorreram entre 1908 e 1910 segundo Ribeiro (2009).

Esse impacto foi tão grande que pelo Governo Federal criou o Serviço de Proteção ao Índio (SPI) para a "pacificação" indígena:

Decreto Lei n. ${ }^{\circ} 8.072$, de 20 de junho de 1910, o SPI teve como objetivo ser um Órgão do Governo Federal encarregado de executar a política indigenista. Sua principal finalidade era proteger os índios e, ao mesmo tempo, assegurar a implementação de uma estratégia de ocupação territorial do país. (FUNAl, 2020d, p. 01).

A criação do SPI modificou a abordagem sobre a questão indígena no país já e em 1911 foi estabelecido um acampamento em Ribeirão dos Patos, sendo está a base de operações do SPI na região durante esse período (FABBRI, CURY, 2019).

Embora, a criação do Serviço de Proteção ao Índio (SPI) para a "pacificação" tenha sido em 1911, há registro que a primeira "pacificação" ocorreu em 1912, a noroeste de São Paulo, já que essa região era povoada pelos Kaingang. Esta operação foi primeiramente conduzida pelo Tenente Manoel Rabelo, depois, até a estabilização foi conduzida por Luiz Bueno Horta Barbosa um professor universitário que lutava pelas causas indígenas de acordo com Ribeiro (1988).

O MHPIV (2020) destaca que o trabalho de "pacificação" dos Kaingang teve seu início em 1912, sendo que:

o último grupo Kaingang "pacificado" em 1915 - 1916 foram realocados para o Posto Indígena Icatu, local que foi adquirido pelo SPI no ano anterior, e em 1917, por conta de desentendimentos entre os grupos Kaingang, é criado o Posto Indígena Vanuíre (MHPIV, 2020, p. 01).

Para esta "pacificação", dentre os vários mediadores indígenas Kaingang, destacou-se a indígena Vanuíre, como intérprete cantando na língua Kaingang e indo ao encontro dos não indígenas para conversar contribuindo decisivamente para a "pacificação" (RIBEIRO, 1988).

Foram chamados vários Kaingang da bacia do Tibagi e outros intérpretes que participavam da expedição para ajudar nos contatos em "[...] 1912, início da conquista. 
Horta Barboza registra que metade dos Kaingang paulistas morreu de uma epidemia de gripe logo após os primeiros contatos entre 1912 e 1913 [...]" (ISA, 2020, p. 01).

Como ressaltado por Moraes et al. (2016), neste posicionamento complexo social de lutas pela posse de territórios, os povos indígenas vieram ao longo dos séculos, perdendo seus espaços geográficos e observando a dissolução de seus traços culturais, diante da força dos elementos advindos da sociedade, por sua vez, pautada no individualismo e no consumo.

Essas ações são corroboradas por Gonçalves (2007), onde cita que no estado de São Paulo, os Kaingang foram reduzidos a dois pequenos grupos em duas pequeníssimas áreas, Gonçalves (2007) acrescenta que:

A política oficial do SPI, levou para suas áreas, na década de 40, indivíduos e famílias indígenas de outras etnias, o que resultou na quase extinção da língua no Estado de São Paulo. [...] Nos anos 80 a língua Kaingang já era considerada extinta no estado de São Paulo. (GONÇALVES, 2007, p. 02).

Hoje no Oeste Paulista existe três Terras Indígenas sendo:

Terra Indígena Icatu, localizada no município Braúna, com 300,9625 hectares, e dois grupos indígenas Kaingang e Terena (FUNAI, 2020c).

A Terra Indígena Araribá, está localizada no município de Avaí com 2000 hectares, e três grupos indígenas Guarani, Guarani Ñandeva e Terena (FUNAI, 2020b).

E a Terra Indígena Vanuíre, localizada no município de Arco-Íris, com 709 hectares e dois grupos indígenas Kaingang e Krenak com sua maior população (FUNAl, 2020a), porém, além desses grupos a Terra Indígena Vanuíre abriga também outros povos indígenas com menor população, sendo o povo Terena, Aticun, Pankarau, Fulniô e Guarani (MHPIV, 2020).

Logo, ao analisarmos um grupo étnico como inferior, neste momento haverá o ato de discriminação, preconceito. Dambros et al. (2020) percebeu essas características, por acrescentar que:

Na sociedade brasileira ainda existe preconceito, discriminação e exclusão dos indígenas; é preciso avançar no respeito aos direitos dessas pessoas e fortalecer suas próprias instituições, culturas e tradições, além de continuar seu desenvolvimento de acordo com suas necessidades e aspirações. (DAMBROS et. al, 2020, p. 390).

A população indígena, como um todo percebe essa segregação, esse apagamento, que a sociedade insiste em aplicar nos povos indígenas. Fernandes e Piovezana (2015) explicita o sentimento destes por concluir que: "[...] nossas escolas, mídia e demais 
circuitos culturais não são alimentados pelos saberes indígenas. O senso comum, nesta situação, é uma armadilha que nos prende nas ilusões do ecologicamente correto [...]" (FERNANDES; PIOVEZANA, 2015, p. 115).

\section{Etnodesenvolvimento do Grupo Kaingang do Oeste Paulista, na Terra Indígena Vanuíre}

A maneira de como os indígenas interagem com ambiente em que vivem oferece informações enriquecedoras sobre suas relações ecológicas e culturais desses grupos.

A maioria dos grupos indígenas do Brasil praticam a agricultura, e com o grupo Kaingang não é diferente, este grupo têm na agricultura uma das formas de promover sua economia.

D'Angelis e Veiga (2009) explica que no cultivo da terra tradicionalmente, antes da chegada dos brancos, eles plantavam milhos (algumas variedades), feijão (um tipo de feijão fava) e morangas.

Dentre os plantios, destaca-se mandioca, milho, amendoim, e dentre esses alimentos reforça-se a mandioca como a principal atividade, pois dela é feito o beiju alimento típico Kaingang (BORELLI, 1984; MELATTI, 1994).

Após o contato com o não indígena "[...] Serviço de Proteção aos Índios (SPI), início do século $X X$, diversificaram mais a sua produção agrícola incorporando, por exemplo, 0 feijão [...]" (PINHEIRO, 1992, p. 62).

Além dos sustentos já mencionados, a agricultura também é uma forma de se organizarem e produzirem outros tipos alimentos como: verduras, legumes e grãos, evitando a carência, de alguns mantimentos segundo Lima (2019).

Faz-se uma ressalva para o plantio de árvores frutíferas, na maior parte das casas do grupo Kaingang da Terra Indígena Vanuíre, possuem plantio de pomares, temperos, hortaliças, e algumas ervas como mate e raízes (PINHEIRO, 1992; LIMA, 2020).

As famílias costumam realizar atividades agroecológicas, por exemplo, compostagem para uma melhor qualidade nas terras de sua agricultura, as atividades de economia são facilitadas porque intrinsecamente, faz parte da natureza indígena promover afazeres de autossustento, conforme relata Luciano (2006).

A produção do plantio e o cultivo é muito importante para os povos indígenas Kaingang da Terra Indígena Vanuíre localizado no município de Arco-Íris interior do estado de São Paulo.

A Comissão Pró-Índio no Estado de São Paulo (CPISP) relata algumas atividades relacionadas a economia da Terra Indígena Vanuíre ao citar Herrero (2016, apud CPISP, 2020) onde este conclui que: 
Apesar das condições adversas históricas, a Aldeia Vanuíre [...]. Na área há cultivo de ervas medicinais e plantas que geram sementes para o artesanato. Plantam batata, mandioca, milho, feijão, amendoim e abóbora para vender e criam um pouco de gado. Cultivam verduras e legumes nas hortas ao redor de suas casas e contam o reforço das frutas dos pomares. Há ainda a criação de galinhas e porcos. As aposentadorias, o benefício do programa bolsa família e o trabalho esporádico e sazonal, mal remunerado nas fazendas da região somamse para compor a renda das famílias (HERRERO, 2016, p. 02).

Um dos costumes do grupo Kaingang, é se organizarem de forma que todos os membros da família participem das atividades agrícolas e culturais, desde os mais jovens aos mais velhos, desta forma eles já desenvolvem junto aos mais jovens o diálogo da memória da cultura tradicional.

Algumas dessas atividades são relatadas por D'Angelis e Veiga (2009), entre tais atividades agrícolas e culturais, no passado os Kaingang tinham quatro fontes de alimento: a coleta, a caça, a pesca e a agricultura. Acrescenta-se ainda o hábito do chimarrão, que é multissecular entre alguns grupos Kaingang.

Gonçalves (2007) reconhece essas atividades agrícolas e culturais, pois ele relata que:

\footnotetext{
Economicamente os Kaingang organizaram-se sobre uma economia baseada na caça, pesca coleta e agricultura complementar, mas atualmente a agricultura é o elemento básico da sua economia, ao lado de famílias que dependem exclusivamente da venda de seus artesanatos. (GONÇALVES, 2007, p. 06).
}

O grupo Kaingang da Terra Indígena Vanuíre, como uma forma de promoverem sua economia, também realizam pequenas trilhas em seus territórios com o público visitante apresentando sua cultura, cobrando um valor simbólico para contribuição da economia indígena.

São momentos de aprendizado, em que o indígena demonstra seu respeito pela natureza, transmitem seu conhecimento no decorrer da trilha, explicando a importância de cada, árvores, plantas e ervas nativas da região, e sua vivência com os mais velhos.

D'Angelis e Veiga (2009) ressalta que em muitos lugares se plantam árvores frutíferas, como butiá, mamão, entre outros, e em vários lugares a plantação de verduras também é comum.

Outro alimento tradicional Kaingang feito de milho roxo é o lamin, sua forma de preparado também tem sido passada de geração a geração é consumido triturado formando uma pasta, sendo enrolado na folha semelhante a uma folha de bananeira, e levado para assar (CAMPOS, 2014).

No entanto, D'Angelis e Veiga alerta que: 


\begin{abstract}
A maior parte das terras Kaingang hoje se destina a agricultura comercial, sobretudo com plantação de soja, mas também milho e feijão. Foi uma péssima alternativa introduzida pela própria Funai há algumas décadas. Hoje há sérios problemas em algumas áreas por causa disso, com algumas lideranças promovendo concentração da terra. (D'AGELIS; VEIGA, 2009, p. 02).
\end{abstract}

Outra estratégia encontrada pelas mulheres Kaingang da família de Dirce Jorge para fortalecer a cultura e promover uma renda, foi a criação do Museu Worikg (Sol Nascente), dentro da Terra Indígena Vanuíre (FUNAI, 2020a).

O museu foi fundado para guardar os pertences da senhora Jandira, após seu falecimento, "[...] é a nossa fortaleza e foi nossa entrada para chegar ao caminho dos museus [...]" (ISA, 2020, p. 01).

Gazoni (2014) fornece mais detalhes, por citar que:

\begin{abstract}
O museu atenderá interesses relacionados ao fortalecimento de grupos culturais e sociais, geralmente com menor representatividade e seus acervos. A busca de um reajuste na relação com a sociedade passa pela necessidade de maior proximidade do museu com patrimônio não musealizados. Iniciativas de aproximação do museu com o entorno ocorrem em busca de maior representatividade de seus acervos e democratização da instituição. (GAZONI, 2014, p.15).
\end{abstract}

Quando jovem, Dirce Jorge indígena Kaingang, já alertava sua mãe para a necessidade de preservação da cultura, "[...] Dizia que as coisas já haviam mudado, não eram mais como antes, agora existem pessoas não-índias a favor dos indígenas [...]" (DOLCE, 2019, p. 01).

Esse despertar para a preservação da cultura é ressaltado por Gazoni (2014) que destaca o trabalho conjunto realizado para a manutenção do museu:

\begin{abstract}
A aproximação entre esses universos permite que a equipe do museu recolher sentidos patrimoniais diretamente com os 'proprietários' do patrimônio, priorizando o sentido do homem sobre o objeto, tal como no novo museu. (GAZONI, 2014, p.17).
\end{abstract}

Na década de 1990, Pinheiro (1999) destaca que, a venda de artesanato estava começando na Terra Indígena, os compradores não eram constantes e os produtores eram ainda poucos.

Atualmente, o artesanato produzido é uma das principais fonte de renda e economia do grupo Kaingang na Terra Indígena Vanuíre, além da importância econômica, a atividade artesanal representa o resgate de aspectos culturais imprescindíveis à própria identidade indígena. 
E mesmo com dificuldade para encontrar a matéria prima como as sementes para confecção de seus artesanatos em seu território, muitas delas são compradas pelo grupo Kaingang em centros comerciais como relata Melo (2020), em seu depoimento em Saberes e fazeres indígenas.

\section{Considerações finais}

Frente aos objetivos da pesquisa aqui apresentado, em compreender o teor histórico e etnográfico do grupo Kaingang da Terra Indígena Vanuíre, e como promovem sua economia.

Estudando para essa compreensão bibliográfica os conceitos etnodesenvolvimento historicidades desse grupo, o presente artigo demonstra ser complexo e instigante.

Pode-se perceber que o manejo tradicional, para o grupo Kaingang na Terra Indígena Vanuíre, possibilita de maneira equilibrada a retirada de substratos da natureza para colaborar com sua economia, é importante ressaltar para nossa compreensão que, para os povos indígenas, é indissociável a relação entre sustentabilidade e sobrevivência.

Mesmo enfrentando problemas como o desgaste do solo, as famílias indígenas Kaingang buscam na agricultura sua fonte de renda, com plantações de milhos, mandiocas dentre outros discorrido nesse estudo.

Outra fonte de renda vem do artesanato observou-se que mesmo o grupo Kaingang tendo dificuldades em encontrar a matéria prima como algumas sementes para a confecção de seus artesanatos, sendo estes obrigados a buscarem essas sementes em centro comerciais, para poderem exercer sua atividade, mesmo assim eles lutam para a preservação da cultura e com ela buscando sua fonte de economia.

O artesanato para os povos indígenas é um elemento que percorre todas as suas esferas, parte do seu conhecimento, da sua cultura e da sua história está ali, naquela peça confeccionada, ao alcance de todas as pessoas.

Observou-se também enquanto estratégia de economia e fortalecimento da cultura, a criação do museu Worikg (Sol Nascente), dentro da Terra Indígena Vanuíre, pelas mulheres Kaingang da família de Dirce Jorge.

Na parte externa do Museu são colocados os artesanatos para venda, e o público também pode escolher um passeio em uma trilha ecológica.

\section{Referências}

ANDRIOLLI, E. M. CANDIDO, J. E. P. O Kaingang e a produção de alimentos. In:

MERCOSUR. Disponível em:

http://fidamercosur.org/claeh/experiencias/experiencias-en-laregi\%C3\%B3n/939-o-kaingang-e-a-produ\%C3\%A7\%C3\%A3o-de- 
alimentos\#: :text=Os\%20\%C3\%ADndios\%20Kaingang\%20s\%C3\%A30\%20consid erados,ind\%C3\%ADgenas\%20mais\%20populosos\%20no\%20Brasil. Acesso em: 23 set. 2020.

D'ANGELIS, W. R.; VEIGA, J. Alimentação dos kaingang, ontem e hoje. Disponível em: http://www.portalkaingang.org/Alimentacao Kaingang.pdf. Acesso em: 06 set. 2020.

BAPTISTA, J. A fome nos povoados missionais: dinâmicas históricas em meio ao debate sobre a subsistência entre jesuítas e indígenas. Biblos. Rio Grande, v. 22, m. 2. P. 27-38, 2008. Disponível em: https://periodicos.furg.br/biblos/article/view/959. Acesso em: 05 set. 2020.

BORELLI, S. H. S. Os Kaingang no estado de São Paulo: constantes históricas e violência deliberada. In: BORELLI, S. H. S. et al. (orgs.). Índios no Estado de São Paulo: Resistência e Transfiguração. São Paulo: Yankatu, 1984. 152p.

BUSSOLI, J. Territorialidade Kaingang da Comunidade Pó Mág em Tabai, porção sul da Bacia Hidrográfica Taquari-Antas. 2018. Dissertação (Mestrado) - Curso de Ambiente e Desenvolvimento, Universidade do Vale do Taquari - Univates, Lajeado, 20 dez. 2018. Disponível em: https://hdl.handle.net/10737/2470. Acesso em: 29 set. 2020.

CAMPOS, J. S. PESCA DE LOCA KAINGANG E KRENAK: Terra Indígena Vanuíre, Projeto Escola Estadual Índia Vanuíre. Produção Museu Histórico e Pedagógico Índia Vanuíre. Tupã, 2014. 01 DVD (60 min), son., color.

COMISSÃO PRO-INDIO DE SÃO PAULO. Kaingang. Aldeia Vanuíre. 2020. Disponível em: https://cpisp.org.br/indios-em-sao-paulo/povos-indigenas/kaingang Acesso em: 18 nov. 2020.

CURY, M. X. Memórias do Território e Resistencia Kaingang: no oeste de São Paulo. In: CARNEIRO, M. L. T.; ROSSI, M. S. (org). Índios no Brasil vida, cultura e morte. 1. ed. São Paulo: Intermeios, 2019. 299p.

CURY, M. X.; FABBRI, A. Memórias do Território e Resistencia Kaingang: a contribuição e experiência do Museu Índia Vanuíre. In: CARNEIRO, M. L. T.; ROSSI, M. S. (org). Índios no Brasil vida, cultura e morte. 1. ed. São Paulo: Intermeios, 2019. 299p.

DAMBROS, B. et al. O reconhecimento dos direitos dos povos indígenas: Um estudo à luz das Constituições Brasileiras. Revista Jurídica (0103-3506). Jan-mar. 2020 vol.1, edição 58, pp. 573-604. 32p. Disponível em:

https://web.a.ebscohost.com/abstract?direct=true\&profile=ehost\&scope=site\&a uthtype $=$ crawler\&jrnl=01033506\&AN $=142689314 \& \mathrm{~h}=$ AKJ1adrHTqdfNbxN5Kmc WGO88L2VZdMHkvTU6Zw3nlRXSY01G\%2fmeVRTAF8mX2PV1Hno43P6VMQ\%2b3 xAlhwdoK3A\%3d\%3d\&crl=c\&resultNs=AdminWebAuth\&resultLocal=ErrCrlNotA uth\&crlhashurl=login.aspx\%3fdirect\%3dtrue\%26profile\%3dehost\%26scope\%3dsi te\%26authtype\%3dcrawler\%26jrnl\%3d01033506\%26AN\%3d142689314. Acesso em 26 set. 2020

D'ANGELIS, W. R.; VEIGA, J. Alimentação dos kaingang, ontem e hoje. 2009. Disponível em: http://www.portalkaingang.org/Alimentacao Kaingang.pdf. Acesso em: 06 set. 2020.

DOLCE, J. Dirce Lipu Pereira: a pajé Kaingang que voltou a cantar. De olho no ruralista. Disponível em: https://deolhonosruralistas.com.br/2019/03/18/dirce-lipu-pereiraa-paje-que-voltou-a-cantar/. Acesso em: 22 out. 2020.

FERNANDES, Ricardo Cid; PIOVEZANA, Leonel. As perspectivas Kaingang sobre os direitos fundiários e ambientais no sul do Brasil. Ambiente. soc., São Paulo, v. 18, n. 2, pág. 111-128, junho de 2015. Disponível em <http://www.scielo.br/scielo.php?script=sci_arttext\&pid=S1414753X2015000200008\&lng=en\&nrm=iso >. Acesso em 16 de novembro de 2020. http://dx.doi.org/10.1590/1809-4422ASOCEx07V1822015en. 
FUNDAÇÃO NACIONAL DO INDIO. Artesanato promove manutenção da cultura

Kaingang no Sul do país. Disponível em:

http://www.funai.gov.br/index.php/comunicacao/noticias/5043-artesanatopromove-manutencao-da-cultura-kaingang-no-sul-do-pais. . Acesso em: 21 set. 2020.

FUNDAÇÃO NACIONAL DO INDIO. Terra Indígena Vanuíre. Disponível em: https://terrasindigenas.org.br/pt-br/terras-indigenas/3896\#direitos. Acesso em: 16 jan. 2020a.

FUNDAÇÃO NACIONAL DO INDIO. Terra Indígena Araribá. Disponível em: https://terrasindigenas.org.br/pt-br/terras-indigenas/3599. Acesso em: 22 abr. 2020b.

FUNDAÇÃO NACIONAL DO INDIO.. Terra Indígena Icatu. Disponível em: https://terrasindigenas.org.br/pt-br/terras-indigenas/3684. Acesso em: $22 \mathrm{abr}$. 2020c.

FUNDAÇÃO NACIONAL DO INDIO. Política Indigenista. Disponível em: http://www.funai.gov.br/index.php/nossas-acoes/politica-indigenista. Acesso em: 14 nov. $2020 \mathrm{~d}$.

GAZONI, P. M. O contemporâneo no museu: os Kaingang e o Museu Histórico e Pedagógico Índia Vanuíre de Tupã - São Paulo. 2014. Dissertação (Mestrado em Museologia) - Museu de Arqueologia e Etnologia, Universidade de São Paulo. SP. 2014. Disponível em: https://teses.usp.br/teses/disponiveis/103/103131/tde13022015-102749/publico/PatriciaMacielREVISADA.pdf Acesso em: 19 nov. 2020.

GONÇALVES, S. A. Aspecto no Kaingang. 2007. Dissertação (Mestrado em Linguística ao Instituto de Estudos da Linguagem) - Universidade Estadual de Campinas, Instituto de Estudos da Linguagem, Campinas, SP. Disponível em: http://www.repositorio.unicamp.br/handle/REPOSIP/268995. Acesso em: 14 nov. 2020.

INSTITUTO SOCIO AMBIENTAL. Terras Indígenas. Disponível em: https://terrasindigenas.org.br/pt-br/noticia/197662. Acesso em: 06 set. 2020c.

KRENAK, A. Compartilhar Memória. In: DIAS C. L.; CAPIBERIBE, A. (org.). Os índios na constituição. Cotia: Ateliê. 2019. 160p.

LIMA, A. T. Política Pública Indigenista Brasileira: Análise das transformações a partir do estudo de caso da Aldeia Indígena Vanuíre (ARCO-IRIS/SP). 2019. Dissertação (Mestrado em Agronegócio e Desenvolvimento) - Universidade Estadual Paulista de Tupã, Tupã, 2019. Disponível em:

https://repositorio.unesp.br/bitstream/handle/11449/181462/lima at me tupa.pd f? sequence=3. Acesso em: 01 abr. 2020.

LUCIANO, G. S. O Índio Brasileiro: o que você precisa saber sobre os povos indígenas no Brasil de hoje. Brasília: Ministério da Educação, Secretaria de Educação Continuada, Alfabetização e Diversidade; LACED/Museu Nacional, 2006. 233p. Ebook. Disponível em: http://www.educadores.diaadia.pr.gov.br/arquivos/File/cfc/livrocolecao.pdf. Acesso em: 19 set. 2019.

MARANHÃO, F. Povos indígenas no Paraná. Disponível em: http://www.museuparanaense.pr.gov.br/modules/conteudo/conteudo.php?conte udo=68. Acesso em: 21 set. 2020.

MELATTI, J. C. Índios do Brasil. São Paulo: Hucitec. 8. ed. 1994. 220p.

MONTEIRO, J. Vida e morte do índio: São Paulo Colonial. In: BORELLI, S. H. S. et al. (orgs.). Índios no Estado de São Paulo: Resistência e Transfiguração. São Paulo: Yankatu, 1984. 152p.

MORAES, N. R. et al. O conceito de território dentro de comunidades tradicionais brasileiras. Revista Obsenvatório, Palmas, v. 2, n. 2, p. 442-455, out. 2016.

Disponível em: 
https://sistemas.uft.edu.br/periodicos/index.php/observatorio/article/view/2869/ 9042. Acesso em: 19 set. 2020.

MUSEU HISTÓRICO E PEDAGÓGICO INDIA VANUIRE. Os Kaingang. Disponível em: https://www.museuindiavanuire.org.br/india-vanuire/os-kaingang. Acesso em: 11 set. 2020.

PINHEIRO, N. S. OS NÔMADES: Etnohistória Kaingang e seu contexto São Paulo, 18501912. 1992. Dissertação (Mestrado em Ciências e Letras) - Universidade Estadual Paulista de Assis, Assis, 1992. Disponível em: https://repositorio.unesp.br/bitstream/handle/11449/145521/000022454.pdf?seq uence $=1$. Acesso em: 01 abr. 2020.

PINHEIRO, N.S. Vanuíre: Conquista, Colonização e Indigenismo: Oeste Paulista, 19121967. (Tese de Doutorado em História) - Faculdade de Ciências e Letras de Assis - Universidade Estadual Paulista, Assis, 1999. Disponível em: https://repositorio.unesp.br/bitstream/handle/11449/145478/000143349.pdf?seq uence $=1$. Acesso em: 15 nov. 2020.

RIBEIRO, D. Os índios e a civilização. São Paulo: Círculo do Livro. 1988. 460p.

RIBEIRO, B. O Índio na história do Brasil. 12. ed. São Paulo: Global. 2009. 143p.

RODRIGUES, A. R.; NISHIKAWA, L. D. A condição sócio-ambiental na área indígena "índia vanuíre", município de arco-íris, e as Possibilidades de adequação agroecológica e de recuperação florestal. In: Fórum Ambiental da Alta Paulista. 3. 2007, Araporã. Anais. [...]. CEIMAM/UNESP/Fundação Araporã. Disponível em: http://fundacaoarapora.org.br/artigospdf/area indigena.pdf. Acesso em: 05 set. 2020.

RODRIGUES, A. R.; NISHIKAWA, L. D. A compreensão do território Kaingang no Oeste Paulista a partir da cultura material: possibilidades interpretativas na análise arqueológica. São Paulo: Revista Museu Arqueologia Etnologia, n. 27, p. 44-54, 2016. Disponível em: www.revistas.usp.br. Acesso em: 15 jul. 2020.

SILVA, J. B. S.; LAROQUE, L. F. S. A história dos Kaingang da terra indígena Linha Glória, Estrela, Rio Grande do Sul/Brasil: sentidos de sua (re)territorialidade. Soc. nat., Uberlândia, v. 24, n. 3, p. 435-447, dec. 2012. Available from $<$ http://www.scielo.br/scielo.php?script=sci_arttext\&pid=S1982$45132012000300005 \& \operatorname{lng}=\mathrm{en} \& \mathrm{nrm}=\mathrm{iso}>$. Acesso em: 18 nov. 2020. https://doi.org/10.1590/S1982-45132012000300005.

VEIGA, J. Aspectos fundamentais da cultura Kaingang. Campinas: Curt Nimuendajú, 2006. 254. 


\section{Crevisto Observatório}

\section{ABSTRACT:}

This article aims to describe the historical and ethnographic content of the Kaingang group from Oeste Paulista, in the Indigenous Land Vanuíre, and how they promote their economy. The Kaingang are peoples belonging to the Macro-Jê linguistic group, and the Jê family is considered one of the largest indigenous groups from the population point of view. The methodology adopted for the development of this article is based on bibliographic and descriptive typology, using documentary research as a technique. It is hoped to obtain, with this article, a systematic set of information, which, when reaching the objective of the work, can contribute to a better understanding of the economy of the Kaingang group in Western São Paulo, in the Indigenous Land Vanuíre.

KEYWORDS: Ethnodevelopment; Kaingang; Terra Indígena Vanuíre.
Kaingang del Oeste Paulista, en la Tierra Indígena Vanuíre, y cómo promueven su economía. Los Kaingang son pueblos pertenecientes al grupo lingüístico Macro-Jê, y la familia Jê es considerada uno de los grupos indígenas más grandes desde el punto de vista poblacional. La metodología adoptada para el desarrollo de este artículo se basa en la tipología bibliográfica y descriptiva, utilizando como técnica la investigación documental. Se espera obtener, con este artículo, un conjunto sistemático de información que, al alcanzar el objetivo del trabajo, puede contribuir a una mejor comprensión de la economía del grupo Kaingang en el Oeste de São Paulo, en la Tierra Indígena Vanuíre.

PALABRAS CLAVE: Etnodesarrollo; Kaingang; Terra Indígena Vanuíre.

\section{RESUMEN:}

Este artículo tiene como objetivo describir el contenido histórico y etnográfico del grupo 